\title{
Attitudes towards those bereaved by a suicide: a population-based, cross-sectional study in rural Japan Sachiko Minamizono*1, Yutaka Motohashi ${ }^{1}$, Masako Yamaji ${ }^{2}$ and Yoshihiro Kaneko ${ }^{1}$
}

\author{
Address: ${ }^{1}$ Department of Public Health, Akita University School of Medicine, Akita, Japan and ${ }^{2}$ Faculty of Health and Medicine Care, Saitama \\ Medical University, Saitama, Japan \\ Email: Sachiko Minamizono* - sachikot@med.akita-u.ac.jp; Yutaka Motohashi - motohasi@med.akita-u.ac.jp; \\ Masako Yamaji - yamaji@saitama-med.ac.jp; Yoshihiro Kaneko - kaneko@med.akita-u.ac.jp \\ * Corresponding author
}

Published: 25 September 2008

BMC Public Health 2008, 8:334 doi: I0.I |86/|47|-2458-8-334

This article is available from: http://www.biomedcentral.com/147I-2458/8/334

(c) 2008 Minamizono et al; licensee BioMed Central Ltd.

This is an Open Access article distributed under the terms of the Creative Commons Attribution License (http://creativecommons.org/licenses/by/2.0), which permits unrestricted use, distribution, and reproduction in any medium, provided the original work is properly cited.

\begin{abstract}
Background: Family or friends bereaved by suicide are at risk of experiencing complications because of attitudes regarding suicide. It is important that individuals close to those grieving after a death by suicide demonstrate adequate knowledge and compassionate attitudes. To this end, we examined the factors that contribute to attitudes toward persons bereaved by the suicide of a family member or friend, and perceptions of suicide prevention and the promotion of mental health.

Methods: A total of $5 \mathrm{I} 54$ residents of a rural town in northern Japan aged 30-69 years completed a crosssectional questionnaire. The questionnaire gathered data about demographic variables, depressive symptoms, and issues related to suicide including personal experience of an acquaintance's suicide, attitudes towards those bereaved by suicide, and perceptions regarding suicide prevention. Factors related to these attitudes and perceptions were analysed using logistic regression models.

Results: Overall, $67.5 \%$ of respondents demonstrated appropriate attitudes towards those bereaved by suicide; $30.4 \%$ of responses were undetermined, and $2.1 \%$ were inappropriate. Undetermined attitudes were associated with male gender (adjusted OR I.42, 95\% Cl $=1.26-1.6 \mathrm{I}$ ), younger age $(2.64,2.12-3.29$ ), lower education level (I.32, I.07-I.62), greater severity of depression (3.8I, 2.80-5.20), and lack of personal experience of an acquaintance's suicide $(1.39,1.22-1.57)$. Inappropriate attitudes were associated with male gender (adjusted OR I.98, 95\% Cl = I.33-2.94), lower education level (2.55 I.34-4.83), and greater severity of depression (6.93,3.52-13.67). Overall, $16.0 \%$ demonstrated passive thoughts regarding suicide prevention and the promotion of mental health in the community, and were associated with male gender (I.22, I.04-1.42), younger age (2.72, 2.03-3.65), lower education level (1.32, I.02-1.71), and greater severity of depression $(4.94,3.58-6.82)$.
\end{abstract}

Conclusion: Factors that contributed to undetermined attitudes included male gender, younger age, lower education level, greater severity of depression, and lack of personal experience of an acquaintance's suicide. Passive thoughts regarding suicide prevention and the promotion of mental health were associated with male gender, younger age, lower education level, and greater severity of depression. 


\section{Background}

Grieving the loss of a family member or friend is a normal process. However, some grief reactions are subject to complications that may seriously compromise the health of the bereaved. For example, the loss of a close relative or friend by sudden traumatic death or suicide can complicate grieving. Farberrow et al. [1] suggested that the process of bereavement is more difficult for those bereaved by a suicide, especially during the first year, as compared to those bereaved by a death from natural causes.

Complicated grief may increase the risk of intense and prolonged mourning, depressive or anxiety disorders, and poor physical health [2,3]. In particular, suicide represents a factor that contributes to the complicated grief reactions of those affected, and complicated grief reactions may place such bereaved persons at risk for long-term dysfunction. Latham et al. [4] suggested that complicated grief is an independent psychiatric risk factor for suicidal thoughts and actions. In fact, the suicide of a spouse increases the suicide risk of the surviving spouse [5]. For these reasons, it is critical that appropriate support is available for individuals who have lost a loved one to suicide.

Early studies examining the effects of post-suicide support on grieving family members focused on professional interventions (i.e., interventions by physicians, nurses, and therapists) by gathering data from the bereaved [6$10]$. It is widely believed that earlier post-suicide interventions are correlated with better outcomes [11]. However, there has been a notable absence of population-based studies examining attitudes towards those grieving a death by suicide.

Two studies examined the responses of college students to acquaintances grieving a death by suicide $[12,13]$. According to one study, respondents experienced greater difficulty talking with and expressing sympathy for family members bereaved by suicide as compared to family members bereaved by a death that was accidental or from natural causes. The other study reported that students tended to attribute more blame to those bereaved by a death by suicide than to those grieving a death resulting from other causes. David et al. [14] suggested that the selfblame and guilt that already haunt those dealing with the suicide of a loved one may receive reinforcement from their community. In view of the aforementioned findings that those grieving a death by suicide already face higher risks for complicated grief, it becomes clear that social reinforcement of the self-blame and guilt experienced by those bereaved by suicide requires replacement with community attitudes that reflect knowledge about suicide and compassion for the bereaved.
Despite the importance of this issue, we know of no study that has examined the factors that contribute to community (e.g., neighbours, workmates, and friends) attitudes towards people bereaved by the suicide of a friend or family member. However, the development of effective educational approaches requires relevant data. Therefore, we examined attitudes towards those bereaved by suicide and perceptions of suicide prevention and the promotion of mental health in a rural region of Japan.

\section{Methods}

\section{Sample and procedure}

We used a sample drawn from a rural town in Akita Prefecture, located in northern Japan. Annual mortality rates for deaths attributed to suicide in Japan and in Akita Prefecture in 2004 were 23.8 (males: 35.2; females: 12.8) and 42.1 (males: 65.7; females: 20.7) per 100,000 people, respectively. Since 1995, Akita Prefecture has recorded the highest suicide-related mortality rates in Japan. In 2004, the town that we studied recorded a suicide-related mortality rate of 47.3 per 100,000 . Since 2006 , this town has organised lectures on suicide and encouraged appointments at mental health counselling services to prevent suicide and promote mental health.

We conducted a survey from July through September 2005 using community volunteers to distribute questionnaires to all households and then collect them 2 weeks later. Our target population consisted of town residents aged 30 to 69 (institutionalised residents were excluded). Of 23,815 total residents, 7521 met these screening criteria. A total of 6383 residents responded to this survey (i.e., a response rate of $84.9 \%$ ).

\section{Questionnaire}

The questionnaire obtained data on demographic variables, educational history, and issues related to suicide. The latter included personal experience of an acquaintance's suicide (i.e., "Did you personally know anyone who died by committing suicide?"); attitudes towards those bereaved by a suicide (i.e., "If someone you know lost a family member or a close friend by suicide, how would you react to them?" The options were: offer to talk, watch calmly, not want involvement, or "don't know"); and perceptions regarding suicide prevention and the promotion of mental health in the community (i.e., "In your opinion, what is the attitude of your community towards efforts to prevent suicide and improve mental health?" The options were: "favourable," "unfavourable," or "don't know").

Educational background was classified into three levels: completed compulsory education (9 years or less); high school graduate (10-12 years); junior college graduate, 
vocational school graduate, or other higher education (more than 13 years).

The severity of depression was assessed using the Zung self-rating depression scale (SDS) [15]. Respondents were classified into four levels: normal (a raw score of $<40$ ); mild (a raw score of 40-47); moderate (a raw score of 4855 ); and severe (a raw score of $\geq 56$ ).

\section{Statistical Analysis}

Data on attitudes towards those bereaved by a suicide were classified into three groups of appropriate, undetermined, and inappropriate: offer to talk and watch calmly were classified as indicators of appropriate attitudes, "don't know" was undetermined, and "not want involvement" was inappropriate. Perceptions regarding suicide prevention and the promotion of mental health in the community were classified into two groups: responses representing favourable opinions were classified as "positive" thoughts, whereas responses representing unfavourable opinions or "don't know" were classified as "passive" thoughts. Logistic regression analyses identified factors contributing to undetermined attitudes and inappropriate attitudes toward the bereaved and compared these with appropriate attitudes and to passive thoughts regarding suicide prevention and the promotion of mental health in the community. For all statistical tests, two-tailed tests were used to determine statistical significance at $\mathrm{P}<0.05$. Statistical analyses were conducted using SPSS version 11.5 software (SPSS Inc.).

This survey was approved by the Ethics Committee of the School of Medicine at Akita University.

\section{Results}

Data were obtained from respondents regarding the key areas under study (Table 1 ). Of the 6383 community residents who returned questionnaires, 5154 (80.7\%) gave complete answers for all variables included in the logistic regression analysis (Table 1). Data on the prevalence of depression indicated that $19.4 \%$ of the total sample reported moderate depression and $4.1 \%$ reported severe depression.

Half of all respondents indicted that at least one of their acquaintances had committed suicide. Slightly more than two-thirds of respondents demonstrated "appropriate" attitudes towards those bereaved by a suicide (i.e., $23.0 \%$ would offer to talk and $44.5 \%$ would watch calmly), $30.4 \%$ demonstrated "undetermined" attitudes, and $2.1 \%$ demonstrated "inappropriate" attitudes. Overall, 16.0\% demonstrated passive thoughts about suicide prevention and the promotion of mental health in the community.
Table 2 presents the results of the logistic regression analyses, comparing "appropriate" attitudes towards those bereaved by a suicide, "undetermined" attitudes associated with male gender (adjusted OR 1.42, 95\%CI $=1.26-$ $1.61)$, younger age $(2.64,2.12-3.29)$, lower education level $(1.32,1.07-1.62)$, greater severity of depression (3.81,2.80-5.20), and lack of personal experience of an acquaintance's suicide (1.39, 1.22-1.57). "Inappropriate" attitudes were associated with male gender (adjusted OR $1.98,95 \% \mathrm{CI}=1.33-2.94)$, lower education level $(2.55$, 1.34-4.83), and greater severity of depression (6.93, 3.52-13.67). Both "undetermined" and "inappropriate" attitudes were related to male gender, lower education level, and greater severity of depression.

Passive thoughts regarding suicide prevention and the promotion of mental health in the community were associated with male gender (adjusted OR 1.22, 95\% CI = $1.04-1.42)$, younger age $(2.72,2.03-3.65)$, lower education level $(1.32,1.02-1.71)$, and greater severity of depression $(4.94,3.58-6.82)$.

\section{Discussion}

Factors that contributed to "undetermined" attitudes included male gender, younger age, lower education level, greater severity of depression, and lack of personal experience of an acquaintance's suicide. Passive thoughts regarding suicide prevention and the promotion of mental health in the community were significantly associated with male gender, younger age, lower education level and greater severity of depression.

Many of the studies have reported that female gender is associated with a higher prevalence of poor mental health status than male [16-24]. Vahtera et al. [20] suggested that women are more affected by the aftermath of death or illness in their extended family than are men. Two studies have found that women tend to complain about stressful interpersonal events, whereas men tend to complain about stressful legal and work-related events [21,22]. Another review, however, suggested that men were more vulnerable to stressful events such as the loss of their partner [25]. Gender differences in the vulnerability to stressful life events were uncertain. Our results indicated that women would feel deeper sympathy than men for those mourning a death by suicide and might be more sensitive to bereaved individuals. Determining effective social support from within the community for individuals grieving the suicide of a friend or family member will require a consideration of gender differences.

Younger people tended to show "undetermined" attitudes towards those bereaved by suicide more than older people did. We considered the possibility that this association may be due to the relative inexperience of young people 
Table I: Characteristics of study participants.

\begin{tabular}{|c|c|c|}
\hline Variable & Subgroup & $\%(N=5154)$ \\
\hline \multicolumn{3}{|c|}{ Age (years) } \\
\hline & $30-39$ & 18.7 \\
\hline & $40-49$ & 27.4 \\
\hline & $50-59$ & 32.5 \\
\hline & $60-69$ & 21.4 \\
\hline \multicolumn{3}{|l|}{ Gender } \\
\hline & Male & 47.9 \\
\hline & Female & 52.1 \\
\hline \multicolumn{3}{|c|}{ Educational background (years) } \\
\hline & 9 or less & 23.3 \\
\hline & $10-12$ & 55.2 \\
\hline & 13 or more & 21.5 \\
\hline \multicolumn{3}{|c|}{ Self-rated depression scale } \\
\hline & Normal & 35.3 \\
\hline & Mild & 41.2 \\
\hline & Moderate & 19.4 \\
\hline & Severe & 4.1 \\
\hline \multicolumn{3}{|c|}{ Personal experience of an acquaintance's suicide } \\
\hline & Yes & 52.6 \\
\hline & No & 47.4 \\
\hline \multicolumn{3}{|c|}{ Attitude toward those bereaved by a suicide } \\
\hline & Offer to talk & 23.0 \\
\hline & Watch calmly & 44.5 \\
\hline & Do not want to be involved & 2.1 \\
\hline & Do not know & 30.4 \\
\hline \multicolumn{3}{|c|}{ Perceptions regarding suicide prevention and the promotion of mental health in the community } \\
\hline & Favorable & 84.0 \\
\hline & Unfavorable & 1.1 \\
\hline & Do not know & 14.9 \\
\hline
\end{tabular}

with bereavement. Although there are no data on the relationship between age and attitudes towards those bereaved by a suicide, studies of the relationship between age and worry (i.e., as assessed by Worry Scale or the Penn State Worry Questionnaire) show that older adults have reported low levels of worrying $[26,27]$. Powers et al. reported that the elderly worry significantly less than those who are relatively young [28]. These authors interpreted these results in terms of lifecycle span and experience. Our results support their findings.

The correlation between passive thoughts regarding suicide prevention and the promotion of mental health in the community and younger age may be understood as a result of disinterest owing to a relative lack of experience of young people with death from any cause.

Many studies have reported significant correlations between level of education and mental health status [23,24,29-31]. Wolff et al. [32] reported that attitudes of goodwill towards people suffering from mental illness were significantly associated with higher levels of education. It is possible that people with lower levels of education express unhelpful attitudes towards those grieving the suicide of a loved one because of a general ignorance about mental health issues. For example, Kaneko et al. [33] reported that low mental health literacy was strongly associated with low levels of education. People with low levels of education may display the undetermined or inappropriate attitudes reported here because they know less about suicide and mental illness.

Beck et al. [34] proposed that depression emerges from dysfunctional cognitions that initiate and maintain the emotional, motivational, and behavioural symptoms that define this condition (e.g., dysphoric mood, lack of motivation, and low energy level). Additionally, the features of depression include reduced energy and diminished activity [35]. These symptoms of depression are consistent with our finding of an association between inappropriate or undetermined attitudes, and greater severity of depression.

Personal experience, or the lack thereof, of involvement with individuals who commit suicide appears to affect attitudes towards those grieving a death by suicide. Addison et al. [36] reported that people who had personal experience of people suffering from mental illness were 
Table 2: Multiple logistic analysis for attitudes toward those bereaved by a suicide.

\begin{tabular}{|c|c|c|c|c|c|c|}
\hline \multirow[b]{3}{*}{ Variable } & \multicolumn{4}{|c|}{ Attitude toward those bereaved by a suicide } & \multirow{2}{*}{\multicolumn{2}{|c|}{$\begin{array}{c}\text { Perceptions of suicide prevention } \\
\text { Passive thoughts }(\mathrm{N}=824) / \text { Positive } \\
\text { thoughts }\end{array}$}} \\
\hline & \multicolumn{2}{|c|}{$\begin{array}{c}\text { Undetermined attitudes }(\mathrm{N}=1568) / \\
\text { Appropriate attitudes }\end{array}$} & \multicolumn{2}{|c|}{$\begin{array}{l}\text { Inappropriate attitudes }(\mathrm{N}=108) / \\
\text { Appropriate attitudes }\end{array}$} & & \\
\hline & Adjusted OR & $95 \% \mathrm{Cl}$ & Adjusted OR & $95 \% \mathrm{Cl}$ & Adjusted OR & $95 \% \mathrm{Cl}$ \\
\hline \multicolumn{7}{|l|}{ Age (years) } \\
\hline $30-39$ & 2.64 & $2.12-3.29$ & 1.11 & $0.53-2.33$ & 2.72 & $2.03-3.65$ \\
\hline $40-49$ & 1.84 & $1.49-2.27$ & 1.21 & $0.64-2.30$ & 2.20 & $1.65-2.92$ \\
\hline $50-59$ & 1.49 & $1.23-1.80$ & 1.25 & $0.74-2.12$ & 2.05 & $1.58-2.66$ \\
\hline $60-69$ & Reference & & Reference & & Reference & \\
\hline \multicolumn{7}{|l|}{ Gender } \\
\hline Male & 1.42 & $1.26-1.61$ & 1.98 & $1.33-2.94$ & 1.22 & $1.04-1.42$ \\
\hline Female & Reference & & Reference & & Reference & \\
\hline \multicolumn{7}{|l|}{$\begin{array}{l}\text { Educational } \\
\text { background } \\
\text { (years) }\end{array}$} \\
\hline 9 or less & 1.32 & $1.07-1.62$ & 2.55 & $1.34-4.83$ & 1.32 & $1.02-1.7 \mid$ \\
\hline $10-12$ & 1.30 & $1.11-1.52$ & 1.18 & $0.67-2.08$ & 1.10 & $0.90-1.34$ \\
\hline 13 or more & Reference & & Reference & & Reference & \\
\hline \multicolumn{7}{|l|}{$\begin{array}{l}\text { Self-rated } \\
\text { depression scale }\end{array}$} \\
\hline Normal & Reference & & Reference & & Reference & \\
\hline Mild & 1.33 & I.15-I.54 & 0.79 & $0.48-1.28$ & 1.40 & $1.15-1.70$ \\
\hline Moderate & 2.00 & $1.68-2.38$ & 1.69 & $1.00-2.87$ & 2.40 & $1.94-2.98$ \\
\hline Severe & 3.81 & $2.80-5.20$ & 6.93 & $3.52-13.67$ & 4.94 & $3.58-6.82$ \\
\hline \multicolumn{7}{|l|}{$\begin{array}{l}\text { Personal } \\
\text { experience of an } \\
\text { acquaintance's } \\
\text { suicide }\end{array}$} \\
\hline Yes & Reference & & Reference & & Reference & \\
\hline No & 1.39 & $1.22-1.57$ & 1.03 & $0.69-1.54$ & 1.13 & $0.97-1.32$ \\
\hline
\end{tabular}

Multiple logistic regression models were adjusted for all items listed in the table.

OR: Odds ratio $\mathrm{Cl}$ : Confidence interval

generally more positive in their attitudes towards people with mental illness compared to those who had no such experience. Our results support the notion that personal experience affects attitudes towards others who are similarly situated. Harwood et al. [37] reported that relatives and friends grieving a death by suicide scored higher than those grieving deaths by other causes in measurements of stigma, shame, sense of rejection, and unique reactions. They found that bereavement following suicide affects not only family but also friends and neighbours. This may explain our finding that appropriate attitudes in the form of expressions of feelings for those mourning a death by suicide is related to a history of personal contact with someone who commits suicide as compared with undetermined attitudes.

Those who displayed undetermined and inappropriate attitudes towards those bereaved by a suicide tended to focus less on the bereaved persons than did those who displayed appropriate attitudes. We categorised "offering to talk" as an appropriate attitude. However, those who indicted they would offer to talk also require education about appropriate ways of talking, language use and grief procedures. Further studies will be needed to improve the social support for those bereaved by suicide and to reduce their psychological burden.

Several limitations pertaining to our study should be noted. Because we used a cross-sectional design, we could not determine causal relationships. Second, the use of a self-administered questionnaire may have led to reporting bias, perhaps especially in relation to items about personal experience of an acquaintance's suicide. Although this may have had a role in the responses proffered by older subjects, similar results were obtained when the sample was stratified by age. Third, our study did not include other causes of death such as natural or accidental death. However, some studies have indicated that the social response to death by suicide differs from responses to other causes of death including natural death $[12,13]$. Therefore, we consider that our results sufficiently should reflect attitudes toward those bereaved by a suicide. Strat- 
egies for improving attitudes and perceptions within the social network of an individual who is bereaved by a suicide should be helpful for the individual afflicted by grief.

Of the 6383 respondents, 5154 answered all of the items used in the logistic regression analyses. The analyses included $68.5 \%$ of residents in the survey area aged 30-69 years. The percentage of unanswered questions were respectively as follows: gender, 2.0\%; age, 2.6\%; level of education, $1.7 \%$; level of depression, $13.1 \%$; and personal experience of an acquaintance's suicide, 3.4\%. Of the 1229 respondents who did not complete the questionnaire, $41.6 \%$ were male, $10.6 \%$ were aged in their 30 s, $12.8 \%$ had an educational background of 13 or more years, $30.3 \%$ had no depressive symptoms (normal) based on a self-rated depression scale, and $41.9 \%$ had an acquaintance who had committed suicide. Males, younger people, those with higher levels of education, those with no depressive symptoms, and those who had personal experience of an acquaintance's suicide returned questionnaires with significantly more complete answers than did others. No statistically significant differences with respect to attitudes towards those bereaved by suicide appeared between complete responders and incomplete responders. However, a statistically significant difference appeared between complete and incomplete responders with regard to perceptions regarding suicide prevention and mental health promotion the community. Levels of concern about suicide among the residents questioned may have influenced these differences.

The community of the area that we studied experiences many deaths by suicide. Prevention of suicides is needed. In developing effective community suicide prevention programs, our results should be taken into account and utilised to educate the community regarding appropriate attitudes and actions.

\section{Conclusion}

Undetermined attitudes towards those bereaved by a suicide were associated with male gender, younger age, lower education level, greater severity of depression, and lack of personal experience of an acquaintance's suicide, as compared to those with appropriate attitudes. Passive thoughts regarding suicide prevention and the promotion of mental health in the community were significantly associated with male gender, younger age, lower education level and greater severity of depression. We hope that our findings will raise awareness of the complications affecting bereavement after a suicide and will improve efforts to help those engaged in the bereavement process. Further research will be required to evaluate the effectiveness of adequate intervention.

\section{Competing interests}

The authors declare that they have no competing interests.

\section{Authors' contributions}

SM, YM, and YK made substantial contributions to the conception and design of the study and were involved in drafting and reviewing the manuscript. MS and MY contributed to the data acquisition process. SM, YM, and YK contributed to the analysis and interpretation of the data. All authors have read and approved the final manuscript.

\section{Acknowledgements}

This work was supported by Misato Cho and a Grant-in-Aid for Scientific Research (No. I5590537) from the Ministry of Education, Culture, Sports, Science, and Technology of Japan.

\section{References}

I. Farberow NL, Gallagher-Thompson D, Gilewski M, Thompson L: Changes in grief and mental health of bereaved spouses of older suicides. I Gerontol 1992, 47(6):P357-P366.

2. Maddocks I: Grief and bereavement. Med J Aust 2003, 179(6 Suppl):S6-S7.

3. Parkes CM: Facing loss. BM] |998, 3 |6(7| 43):|52|-|524.

4. Latham AE, Prigerson HG: Suicidality and bereavement: complicated grief as psychiatric disorder presenting greatest risk for suicidality. Suicide Life Threat Behav 2004, 34(4):350-362.

5. Agerbo E: Midlife suicide risk, partner's psychiatric illness, spouse and child bereavement by suicide or other modes of death: a gender specific study. J Epidemiol Community Health 2005, 59(5):407-4I2.

6. Sakinofsky I: The aftermath of suicide: managing survivors' bereavement. Can J Psychiatry 2007, 52(6 SuppI I): I29S-136S.

7. Pfeffer CR, Jiang H, Kakuma T, Hwang J, Metsch M: Group intervention for children bereaved by the suicide of a relative. I $\mathrm{Am}$ Acad Child Adolesc Psychiatry 2002, 4 I (5):505-5I3.

8. Constantino RE, Bricker PL: Nursing postvention for spousal survivors of suicide. Issues Ment Health Nurs 1996, I7(2): | 3 |- 152.

9. Rogers J, Sheldon A, Barwick C, Letofsky K, Lancee W: Help for families of suicide: survivors support program. Can J Psychiatry 1982, 27(6):444-449.

10. de Groot M, de Keijser J, Neeleman J, Kerkhof A, Nolen W, Burger $\mathrm{H}$ : Cognitive behaviour therapy to prevent complicated grief among relatives and spouses bereaved by suicide: cluster randomized controlled trial. BMJ 2007, 334(760 I):962-963.

II. Karen DM, Edward JD: Family involvement in suicide prevention and postvention: a psychoeducational perspective. In Suicide - an unnecessary death Edited by: Danuta W. Stockholm: Martin Dunitz Ltd; 200I:243-250.

12. Range LM, Thompson KE: Community responses following suicide, homicide, and other deaths: the perspective of potential comforters. J Psychol 1987, I 2 I(2): 193-198.

13. Calhoun LG, Selby JW, Abernathy CB: Suicidal death: social reactions to bereaved survivors. I Psychol 1984, I I6(2d Half):255-26I.

14. Ness D, Pfeffer CR: Sequelae of bereavement resulting from suicide. Am J Psychiatry 1990, I47(3):279-285.

15. Zung W: A self-rating depression scale. Arch Gen Psychiatry 1965, 1 2:63-70.

16. Levav I, Gilboa S, Ruiz F: Demoralization and gender differences in a kibbutz. Psychol Med 1991, 21 (4): 1019-1028.

17. Weich S, Sloggett A, Lewis G: Social roles and gender difference in the prevalence of common mental disorders. $\mathrm{Br} J$ Psychiatry 1998, 173:489-493.

18. Ritsner M, Ponizovsky A, Ginath $Y$ : The effect of age on gender differences in the psychological distress rating of immigrants. Stress Med 1999, I 5:17-25.

19. Cole MG, Dendukuri N: Risk factors for depression among elderly community subjects: a systematic review and metaanalysis. Am J Psychiatry 2003, 160(6): I |47-II 56.

20. Vahtera J, Kivimaki M, Vaananen A, Linna A, Pentti J, Helenius H, Elovainio M: Sex differences in health effects of family death or 
illness: are women more vulnerable than men? Psychosom Med 2006, 68(2):283-29I.

21. Kendler KS, Thornton LM, Prescott CA: Gender differences in the rates of exposure to stressful life events and sensitivity to their depressogenic effects. Am J Psychiatry 200I, I 58(4):587-593.

22. Ritsner M, Ponizovsky A, Nechamkin Y, Modai I: Gender differences psychosocial risk factors for psychological distress among immigrants. Compr Psychiatry 200I, 42(2): I5I-I60.

23. Jenkins R, Lewis G, Bebbington P, Brugha T, Farrell M, Gill B, Meltzer $\mathrm{H}$ : The National Psychiatric Morbidity surveys of Great Britain-- initial findings from the household survey. Psychol Med 1997, 27:775-789.

24. Araya R, Rojas G, Fritsch R, Acuna J, Lewis G: Common mental disorders in Santiago, Chile: prevalence and socio-demographic correlates. BrJ psychiatry 200I, I 78:229-233.

25. Stroebe M, Schut H, Stroebe W: Health outcomes of bereavement. Lancet 2007, 370(9603): 1960-1973.

26. Cappeliez P: Daily worries and coping strategies: implications for therapists. Clin Gerontol 1989, 8(3):70-7I.

27. Hunt S, Wisocki $P$, Yanko J: Worry and use of coping strategies among older and younger adults. J Anxiety Disord 2003, I 7(5):547-560.

28. Powers $C B$, Wisocki PA, Whitbourne SK: Age differences and correlates of worrying in young and elderly adults. Gerontologist 1992, 32(I):82-88.

29. Araya R, Lewis G, Rojas G, Fritsch R: Education and income: which is more important for mental health? J Epidemiol Community Health 2003, 57:501-505.

30. Kesseler RC, McGonagle KA, Zhao S, Nelson CB, Hughes M, Eshleman S, Wittchen HU, Kendler KS: Lifetime and I 2-month prevalence of DSM--R psychiatric disorders in the United States. Results from the National Comorbidity Survey. Arch Gen Psychiatry 1994, 5 I (I):8-19.

31. Taylor R, Page A, Morrell S, Carter G, Harrison J: Socioeconomic differentials in mental disorders and suicide attempts in Australia. Br J Psychiatry 2004, I 85:486-493.

32. Wolff G, Pathare S, Craig T, Leff J: Community attitudes to mental illness. Br J Psychiatry 1996, I 68(2): 183-190.

33. Kaneko Y, Motohashi Y: Male gender and low education with poor mental health literacy: a population-based study. J Epidemiol 2007, I7(4): I |4-II9.

34. Beck AT, Shaw BF, Emery G: Cognitive therapy of depression New York: Guilford Press; 1979.

35. Hale AS: ABC of mental health. Depression. BMJ 1997, 3 I 5(7099):43-46.

36. Addison SJ, Thorpe SJ: Factors involved in the formation of attitudes towards those who are mentally ill. Soc Psychiatry Psychiatr Epidemiol 2004, 39(3):228-234.

37. Harwood D, Hawton K, Hope T, Jacoby R: The grief experiences and needs of bereaved relatives and friends of older people dying through suicide: a descriptive and case control study. Affect Disord 2002, 72(2): I 85-194.

\section{Pre-publication history}

The pre-publication history for this paper can be accessed here:

http://www.biomedcentral.com/1471-2458/8/334/pre pub
Publish with Biomed Central and every scientist can read your work free of charge

"BioMed Central will be the most significant development for disseminating the results of biomedical research in our lifetime. "

Sir Paul Nurse, Cancer Research UK

Your research papers will be:

- available free of charge to the entire biomedical community

- peer reviewed and published immediately upon acceptance

- cited in PubMed and archived on PubMed Central

- yours - you keep the copyright

Submit your manuscript here:

http://www.biomedcentral.com/info/publishing_adv.asp
BioMedcentral 